\title{
Formação crítico-reflexiva de professores mediada por filmes
}

\section{Mônica Ferreira Mayrink}

Professora Doutora do Departamento de Letras

Modernas da FFLCH - USP - Faculdade

de Filosofia, Letras e Ciências Humanas da

Universidade de São Paulo; Pos-Graduação em

Língua Espanhola e Literaturas Espanhola e

Hispano-Americana da FFLCH - USP; São Paulo;

São Paulo; Brasil.

momayrink@usp.br

Resumo: Este artigo relata um estudo que descreve e interpreta o fenômeno da formação crítico-reflexiva de professores mediada por filmes, com base na experiência vivida na disciplina A Escola no cinema: reflexão sobre a prática pedagógica a partir de filmes. A pesquisa foi fundamentada teoricamente nos trabalhos de Dewey, Schön, Freire e Vygotsky, entre outros, para compreender o papel dos filmes como signos mediadores no desenvolvimento críticoreflexivo do professor. Metodologicamente, a pesquisa se apoiou na Abordagem HermenêuticoFenomenológica (van Manen, 1990). A interpretação dos textos revela que o fenômeno em foco se estrutura em torno de quatro temas: Conceitos, Questionamentos, Buscas e Transformações.

Palavras-chave: reflexão-crítica; mediação; filmes
Abstract: This article presents a study that describes and interprets a phenomenon in which participants experienced during the critical reflective teacher education course: "The school in the movies: reflecting upon the pedagogical practice with films". The theoretical underpinnings for this research were the studies developed by Dewey, Schön, Freire and Vygotsky, among others. Methodologically, the study was based on the Hermeneutic-Phenomenological Approach (van Manen, 1990). The results of the interpretations reveal that the structure of the phenomenon investigated was comprised by four themes: Concepts, Inquiries, Searches and Changes.

Key-words: critical reflection; mediation; films 

Professor John Keating: Na minha aula, vocês aprenderão a pensar por si próprios. Aprenderão a saborear palavras e linguagem.

$\mathrm{O}$ que quer que lhes digam, palavras e idéias podem mudar o mundo.

(Sociedade dos Poetas Mortos)

\section{Introdução}

A vivência de experiências de ensino e aprendizagem, aliada à construção de saberes teóricos, revela-se fundamental para a formação do professor. No entanto, a articulação entre esses conhecimentos teóricos e práticos nem sempre se estabelece de forma natural, mas dependem de que sejam criadas oportunidades para o exercício da reflexão, peça-chave no desenvolvimento de uma postura indagadora e crítica do professor.

Em meu percurso como formadora de professores de Língua Espanhola no Ensino Superior, sempre foi recorrente minha busca por estratégias e recursos que pudessem contribuir para que meusalunos desenvolvessem um olhar problematizador e questionador sobre diferentes temas relacionados ao processo de ensinar e aprender línguas. Dentro das limitações impostas pelo currículo, carga horária dos cursos e possibilidades existentes para a realização de estágios de observação e regência de aulas, busquei estabelecer caminhos que abrissem portas para o desenvolvimento da postura reflexiva dos alunos. No entanto, apesar das iniciativas empreendidas, percebi que esses espaços ainda eram insuficientes. Pensando nisso, no primeiro semestre de 2004, ministrei uma disciplina inédita na universidade em que lecionava, que teve como objetivo propiciar condições para que os alunos pudessem refletir, criticamente, sobre a prática pedagógica, utilizando filmes ficcionais cujos roteiros apresentavam professores, alunos e diretores de escola, todos eles 
envolvidos em conflitos que, de alguma maneira, tinham repercussões no processo de ensino-aprendizagem. A disciplina, de caráter eletivo, intitulava-se A Escola no cinema: reflexão sobre a prática pedagógica a partir de filmes e foi objeto de estudo em minha tese de doutorado (MAYRINK, 2007).

Neste artigo, apresento uma síntese dessa pesquisa, que teve como objetivo descrever e interpretar o fenômeno da formação crítico-reflexiva de professores mediada por filmes, do ponto de vista de quem o vivenciou: meus alunos (doze estudantes do curso de Letras e uma do curso de Pedagogia) e eu, professora-pesquisadora. Inicialmente, discuto a teoria que embasa este estudo, no que diz respeito a dois de seus eixos centrais: (a) o conceito de reflexão e reflexão crítica; (b) o conceito de signo mediador e a compreensão de que os filmes podem exercer essa função, contribuindo para o desenvolvimento crítico-reflexivo do professor. Na sequência, traço um panorama do contexto da pesquisa e apresento alguns dos princípios da Abordagem Hermenêutico-Fenomenológica, orientação metodológica que me permitiu descrever e interpretar o fenômeno em foco. Em seguida, ilustro, por meio de textos coletados durante a pesquisa, a interpretação que faço do fenômeno investigado. Na última seção, apresento algumas reflexões finais sobre o papel desempenhado pelos filmes na formação reflexiva dos professores.

\section{Da reflexão à reflexão crítica}

O conceito de reflexão pode ser entendido como parte de um movimento teórico que pretende contribuir para a compreensão do trabalho do professor, segundo esclarece Pimenta (2002). A perspectiva de formação de professores reflexiva tem suas origens nos trabalhos de Dewey. Em sua Teoria das Experiências, o filósofo valoriza a experiência como um aspecto fundamental na 
constituição do indivíduo (DEWEY, 1938/1967). Para ele, o indivíduo se constitui como tal graças às interpretações que dá às experiências pelas quais passa; a articulação dessas experiências, portanto, é fruto da reflexão. Sob o olhar de Dewey (1933, p.100), é preciso entender que a interpretação das experiências somente é possível por meio do pensamento reflexivo cuja função reside em transformar uma situação caracterizada pela obscuridade, dúvida, conflito ou perturbação em uma situação clara, coerente, segura e harmoniosa. Entretanto, a atitude de pensamento reflexivo, segundo o autor, não se manifesta naturalmente, mas precisa ser desenvolvida e, nesse sentido, a educação assume um papel fundamental, pois, por meio dela, o professor pode crescer em sua capacidade reflexiva por meio de práticas que o levem a tomar consciência do processo de reflexão pelo qual está passando e das contribuições que esse processo pode lhe trazer. Porém, conforme alerta Dewey (1933, p.16), o pensamento reflexivo somente se concretiza se houver um desejo real de concretizá-lo.

Partindo das contribuições iniciais de Dewey, Schön $(1983 ;$ 1987) deu maior impulso ao desenvolvimento do conceito de reflexão, ao propor sua epistemologia da prática. O autor identifica como um de seus componentes o conhecimento-na-ação, o qual, segundo ele mesmo explica, tem suas raízes no conceito de "conhecimento tácito" (tacit knowing) proposto por Polanyi (1967). O conhecimento-na-ação pode ser entendido como o saber fazer e, segundo Schön (1987, p.25), o revelamos ao desempenharmos nossa ação de forma espontânea e habilidosa.

Outro importante componente da prática reflexiva identificado pelo autor é a reflexão-na-ação, que corresponde à situação em que "o nosso pensamento serve para reformular o que estamos fazendo enquanto o estamos fazendo" (p.26). Essa forma de reflexão caracteriza-se 
pelos pensamentos do professor que o levam a improvisar e tomar decisões no momento em que está atuando em sala de aula, e que lhe permitem encontrar soluções para os problemas que ali encontra.

Schön (1987) reconhece ainda a importância de se refletir sobre a ação, momento que o professor pensa sobre o que fez em sua aula e descobre de que forma o seu conhecimento-na-ação pode ter contribuído para que tenha alcançado determinados resultados. A reflexão sobre a ação é, portanto, um processo consciente e deliberado.

Ampliando a proposta de Schön, outros pesquisadores avançaram na visão e compreensão do conceito de reflexão, ao acrescentar a ele o componente crítico. Kemmis (1987), Smyth (1992), Zeichner (1993) e Contreras (2002), por exemplo, passam a chamar atenção para as relações entre a prática individual e cotidiana do professor e contextos mais amplos, institucionais e sociais, com implicações políticas e econômicas. Essa perspectiva dialoga com os trabalhos de Freire $(1979 ; 1982)$, autor que compreende que a reflexão é um processo que envolve as relações do homem com o mundo, e que as transformações podem decorrer de sua participação ativa na sociedade. Para isso, segundo Freire (1979; 1982), é necessário estimular a consciência crítica (marcada por uma visão indagadora que se propõe a analisar os problemas de forma profunda), que permitirá ao transformar a realidade.

Essas diferentes luzes que se lançam à reflexão e à reflexão crítica sugerem que é preciso compreender a formação do professor crítico-reflexivo como

"um processo de desenvolvimento da capacidade reflexiva e da consciência crítica que se constrói na relação com o outro e com o mundo, e que permite que o professor questione, analise, interprete e compreenda sua própria ação e a de outros, no amplo universo institucional e social em que se insere." (MAYRINK, 2007, p.20). 
Visto dessa maneira, entendo que o professor crítico-reflexivo se constitui como tal porque vivenciou um processo de desenvolvimento e aprimoramento de sua capacidade de refletir criticamente sobre sua própria ação e sobre a ação de outros professores. Isso quer dizer que a reflexão crítica é um processo mais complexo do que o simples pensar sobre a ação, pois envolve tomada de consciência, análise e questionamento, ações essas que lhe permitem tomar decisões e gerar transformações. Os cursos e programas de formação cumprem aqui um papel essencial, ao serem responsáveis pelo estabelecimento de propostas e definição de estratégias e recursos que colaborem com o desenvolvimento crítico-reflexivo dos professores.

\section{Filmes, mediação e reflexão}

Vygotsky (1930/1998) enfatiza a importância da mediação dos sistemas simbólicos na relação entre o sujeito e o mundo que o cerca. Para o autor (Vygotsky, 1930/1998;1934/1999), os instrumentos e os signos, construídos historicamente, fazem a mediação dos seres humanos entre si e deles com o mundo. A linguagem, por exemplo, é um signo mediador, pois incorpora os conceitos generalizados e elaborados pela cultura humana. Nesse sentido, a função mediadora da linguagem (verbal e nãoverbal) do cinema pode contribuir, em um sentido amplo, para a construção do conhecimento do homem a respeito do mundo que o cerca.

Visto como um elemento que, potencialmente, promove a reflexão crítica, a troca de experiências e idéias e a conseqüente construção e re-construção de conhecimento, o filme pode funcionar como instrumento e também como signo mediador.

Cabe lembrar que, para Vygotsky (1930/1998, p.71), a analogia básica entre signo e instrumento reside 
na função mediadora que os caracteriza e a distinção entre eles se verifica na forma como orientam o comportamento humano:

A função do instrumento é servir como um condutor da influência humana sobre o objeto da atividade; ele é orientado externamente; deve necessariamente levar a mudanças nos objetos. Constitui um meio pelo qual a atividade humana externa é dirigida para o controle e o domínio da natureza. O signo, por outro lado, não modifica em nada o objeto da operação psicológica. Constitui um meio da atividade interna dirigido ao controle do próprio indivíduo; o signo é orientado internamente (p.72-73).

Vygotsky (1930/1998, p. 53) considera a estrutura das operações com signos como mais complexa que a estrutura das formas elementares de comportamento, uma vez que ela "requer um elo intermediário entre o estímulo e a resposta. Esse elo intermediário é um estímulo de segunda ordem (signo), colocado no interior da operação, onde preenche uma função especial; ele cria uma nova relação entre S e R". O psicólogo explica que o signo age sobre o indivíduo, que deve estar ativamente engajado no estabelecimento desse elo. Consequentemente, o simples processo estímulo-resposta é substituído por um ato complexo, constituído por $S$ (estímulo), que gera $R$ (resposta), em decorrência de $X$ (mediação).

À luz da teoria de Vygotsky, os filmes podem se caracterizar ora como instrumentos ora como signos, dependendo do uso que se faz deles. Essa diferença pode ser observada tomando como exemplo o contexto em que se desenvolveu este estudo (no âmbito da disciplina $A$ escola no cinema: reflexões sobre a prática pedagógica a partir de filmes). Muitos dos filmes comerciais trabalhados durante o curso se apresentam, originalmente, como um objeto de 
entretenimento. Sendo assim, seu efeito no espectador pode ser apenas superficial, não cumprindo outra função que não a de lhe proporcionar um momento de lazer. Nessa perspectiva, o filme age como instrumento, com uma influência meramente situacional no espectador.

No entanto, quando incorporados ao contexto específico de um curso ou programa de formação docente, como no caso da disciplina que apresentamos neste estudo, os filmes podem ser utilizados com o objetivo de desencadear uma reflexão crítica sobre a prática pedagógica. Como se verá adiante, ao se fazer um uso consciente dos filmes, estes podem assumir uma nova função: a de signo. Discussões em torno da trama, de seus personagens ou outros elementos, podem dirigir e aguçar o olhar do espectador (o professor), ampliando e enriquecendo sua relação com o filme e, consequentemente, gerando um efeito contínuo (e não situacional, restrito ao momento em que ele o assiste), que pode ter reflexos na sua percepção sobre diversas questões concernentes à prática pedagógica.

Desse modo, o potencial do filme de propiciar ao professor uma oportunidade de viver uma experiência centrada no outro (nos personagens do filme), pode ter uma repercussão individual que enriquece e expande seu contínuo experiencial . Para alguns, porém, o filme pode continuar a cumprir somente a função de instrumento (de entretenimento, por exemplo), dependendo da forma como se dá a sua aproximação com esse objeto (MAYRINK, 2007).

Voltando à proposta de Vygotsky, pode-se fazer uma relação com a operação que se estabelece no contexto de formação de que estou tratando. Aqui, $S$ - a situação corresponde ao visionamento e discussão de cada filme assistido pelos alunos na disciplina $A$ escola no cinema: reflexão sobre a prática pedagógica a partir de filmes, que constitui o contexto mais amplo, o pano de fundo 
que caracteriza o cenário do processo da mediação; $R$ corresponde à reflexão crítica, reação desejada, na forma de auto-reflexões e reflexões compartilhadas pelos alunos; $X$ - a mediação - corresponde aos filmes e às atividades propostas ao longo do curso, que foram utilizados como signos mediadores do processo crítico-reflexivo.

Dessa forma, o filme, entendido como signo mediador, possui o potencial de conduzir os professores em formação "a uma estrutura específica de comportamento que se destaca do desenvolvimento biológico e cria novas formas de processos psicológicos enraizados na cultura" (VYGOTSKY, 1930/1998, p. 54). Esse pensamento de Vygotsky é extremamente importante, pois valoriza o papel que o filme pode desempenhar no desenvolvimento do professor críticoreflexivo, como se verá ao longo deste trabalho.

\section{O olhar interpretativo do fenômeno da formação crítico-reflexiva de professores mediada por filmes}

O olhar interpretativo que orientou este estudo se enquadra nos princípios da Abordagem HermenêuticoFenomenológica (van MANEN, 1990; RICOEUR, 2000; FREIRE, 2006; 2008), que me permitiu proceder à descrição e interpretação do fenômeno da formação crítico-reflexiva de professores, mediada por filmes, visando à visualização de sua estrutura e de sua natureza (essência). Os textos que constituem a base deste estudo foram reunidos ao longo do primeiro semestre de 2004, quando a disciplina $A$ Escola no cinema: reflexão sobre a prática pedagógica a partir de filmes foi ministrada a treze alunos dos cursos de Letras e de Pedagogia de uma universidade de São Paulo.

Como orientação metodológica para o desenho da disciplina, apoiei-me na Abordagem Baseada nas Artes 
(DIAMOND, 1997; 1998) que, por meio de técnicas baseadas nas artes, busca criar oportunidades para que o professor possa atribuir significados para as experiências vividas ao longo de seu desenvolvimento profissional.

Assim como a música, o teatro ou a pintura, os filmes podem ser compreendidos como um objeto que pertence ao mundo das artes e não somente como um recurso que promove entretenimento e fruição de emoções. Eles são também matéria para a construção de conhecimentos e para a educação, como um produto da cultura que pode ser visto, interpretado em seus múltiplos significados e criticado, como aponta Almeida (2001, p.32). Nesse universo, inserem-se os filmes comerciais e ficcionais, utilizados na disciplina em questão com um valor educativo, por sua capacidade de levar o espectador a refletir sobre os conhecimentos novos que apresentam, como ressalta Costa (2005, p.96).

A fim de contribuir para o desenvolvimento gradativo da capacidade crítico-reflexiva de meus alunos, organizei o curso em três momentos. No primeiro momento, os filmes e os tópicos a discutir foram sugeridos por mim, professora-pesquisadora. No segundo momento, os alunos indicaram os tópicos sobre os quais gostariam de refletir e eu selecionei os filmes a serem vistos. No terceiro momento, tanto os filmes quanto os tópicos para reflexão foram propostos pelos alunos.

Ao longo do curso, além de assistirem e discutirem os filmes, os alunos realizaram leituras de textos teóricos e desenvolveram diferentes atividades (individuais e em grupos) que tinham como objetivo desencadear sua reflexão sobre a docência.

Além de reunir as atividades realizadas pelos alunos, procedi à gravação e transcrição das 17 aulas que compreenderam o curso, e esse conjunto de procedimentos me permitiu, em uma primeira fase, 
textualizar as experiências vividas e, depois, estabelecer a rotina de voltar a elas, descrevê-las e interpretá-las na tentativa de compreender a natureza do fenômeno que me propus a estudar.

Seguindo procedimentos condizentes com a Abordagem Hermenêutico-Fenomenológica, procurei me aproximar dos textos por meio de inúmeras leituras, trilhando os caminhos das abordagens holística, seletiva e detalhada, propostas por van Manen (1990, p.93). Desse modo, pude, também, operacionalizar os procedimentos de refinamento e ressignificação sistematizados por Freire (2006; 2008), para chegar à identificação dos temas (bem como de seus desdobramentos em subtemas e subsubtemas) que me permitiram visualizar a estrutura do fenômeno. Foi importante também retornar às experiências vividas por meio dos textos para a validação e confirmação das interpretações, num movimento que caracteriza o chamado ciclo hermenêutico (RICOEUR, 2001) ou ciclo de validação (van MANEN, 1990).

\section{Um percurso reflexivo de formação}

Ao descrever e interpretar cada um dos momentos em que se dividiu a disciplina que é foco deste estudo, pude identificar o percurso reflexivo que foi se delineando ao longo de todo o processo . Na sequência, apresentarei a forma como o fenômeno da formação crítico-reflexiva de professores mediada por filmes foi se apresentando, dentro da particularidade de cada momento do curso.

\subsection{Momento 1}

No momento inicial do curso, que compreendeu as cinco primeiras semanas de aula, desenvolvi atividades que geraram textos que, interpretados, revelaram que o fenômeno em foco, nesse primeiro momento, 
se estruturava em dois grandes temas - conceito e questionamentos - que, por sua vez, se desdobravam em subtemas e vários sub-subtemas.

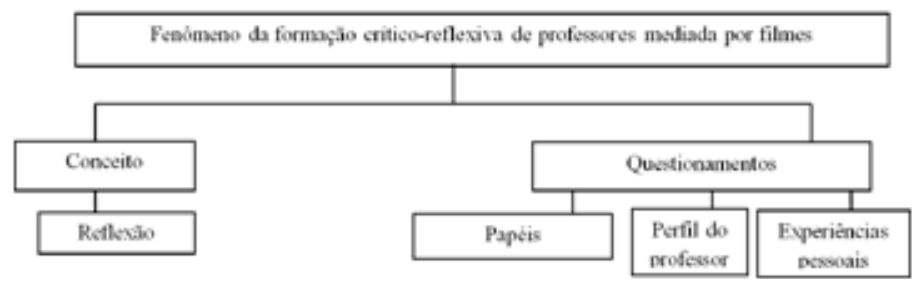

Fig. 1: A estrutura do fenômeno no Momento1

O diagrama ilustra os primeiros passos dados por meus alunos na direção de uma formação críticoreflexiva. As reflexões iniciais aqui desencadeadas se apoiaram, por um lado, em conceitos que propiciaram uma melhor compreensão da prática (crítica e reflexiva) à luz da teoria discutida nas aulas, como mostra o excerto destacado a seguir:

Mônica: (...) O que você entende por professor reflexivo? Se a gente fala em professor reflexivo, o que é isso?

Darlene: Pensar sobre as atitudes, sobre seus atos, postura. (...)

Francis: $A$ realidade, como circula em volta da sala de aula. (...)

Jamile: O professo reflexivo é aquele que provoca a dúvida, provoca revolução no aluno porque o bem estar eterno não tem porque né? (...)

Darlene: Mas, em relação ao que já foi colocado, em relação a ele professor, ao aluno e a comunidade. Tudo isso aí a gente deve fazer em relação ao aluno e a comunidade que nos cerca. Tudo que perpassa por isso né? Inclusive a família.(...) 
Como se pode observar, os alunos se aproximam de uma visão crítica, pois suas falas revelam uma compreensão de que a reflexão deve romper a barreira das paredes da sala de aula, abrindo-se à comunidade e à realidade social na qual ela se insere.

As reflexões, nesse momento do curso, desencadearam também questionamentos que levaram à dúvida e inquietação quanto aos papéis exercidos por diferentes participantes do processo educativo, e ao resgate de experiências aparentemente esquecidas. No que diz respeito ao professor, por exemplo, os alunos o vêem como responsável por estabelecer uma ponte entre o estudante e o conhecimento, de forma que este seja significativo para sua vida. Além disso, entendem que o professor cumpre um importante papel de mediador na construção de uma visão crítica do aluno e de um saber que se expande para fora dos limites de sua sala de aula. É o que evidencia o fragmento abaixo, retirado do relato reflexivo de uma aluna:

O que me chamou atenção [no filme Sociedade dos Poetas Mortos] foi a autonomia do professor e seu modo de se relacionar com seus alunos. Isso prova que um bom professor não é aquele que enche os alunos de conteúdo apenas. Mas aquele que incita e estimula o aluno pela curiosidade a descobrir o que o conteúdo tem de relevante para a sua vida, ou seja, além desse conteúdo fazer parte de uma disciplina, ele precisa ser significativo, assim como o professor ensinava a poesia.

Outro subtema que emergiu dos textos reunidos duranteoMomento1, vinculadoaotema Questionamentos, refere-se às reflexões dos alunos sobre suas experiências pessoais. Observei que eles freqüentemente se remetiam a experiências anteriores para explicar e exemplificar seu ponto de vista a respeito dos assuntos que se colocam em pauta de discussão durante as aulas. Em uma delas, por 
exemplo, ao refletir sobre o papel do professor, uma das alunas deu seu depoimento e outros colegas opinaram, como vemos a seguir:

Inae: A minha professora daqui da Faculdade sabia que eu era funcionária e um dia ela chegou para mim e disse: "se eu fosse você, eu desistia do curso", porque eu não tinha condições de estudar. (...) E aí depois fiz um aprova com uma colega chamada Juliana e nós tiramos 9.0, e a professora me disse:" eu não vou dar 9.0 para você porque você não é capaz de tirar 9.0". Só que aconteceram outras coisas melhores, com outros professores que me mostraram a dificuldades e que me disseram que eu era capaz de ir além. (...)

Geovana: Eu acho que depende do professor. Talvez a maneira como ele trata a situação, porque, por exemplo, o jeito como ele tratou ela não foi algo construtivo. Eu já ouvi alguns professores dizerem que têm que fazer algum tipo de provocação ou elogio para que o aluno desperte, mas eu acho que no caso da Inae não foi isso.

\subsection{Momento 2}

Na interpretação dos textos reunidos no Momento 2, emergiram três temas - questionamentos, conceitos e buscas - que, por sua vez, tiveram vários desdobramentos. É curioso observar que os temas questionamentos e conceitos e alguns sub-subtemas (como as relações entre professor e aluno, o papel da escola e o papel do professor) já haviam se manifestado no momento anterior. No entanto, esses tópicos voltaram a surgir no Momento 2, de uma maneira diferenciada, aprofundando e colocando em pauta discussões antes não desencadeadas. A figura abaixo ilustra a estrutura do Momento 2: 


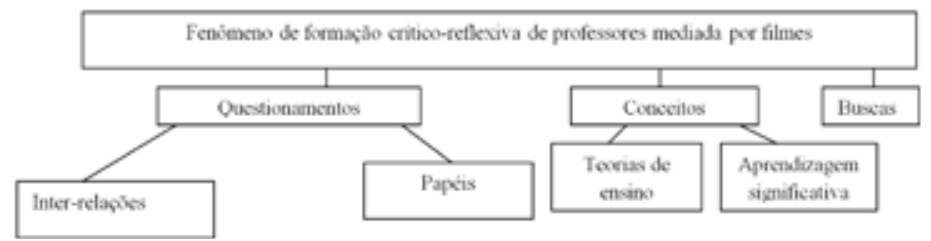

Fig. 2: A estrutura do fenômeno no Momento 2

Como se pode observar no diagrama, o tema questionamentos se apresenta vinculado a dois subtemas - Inter-relações e Papéis. Os excertos a seguir ilustram alguns dos questionamentos surgidos neste momento:

Darlene: Acho que a maior dificuldade do professor é justamente achar esse meio termo.

Anna: Mas acho que nem é tão difícil, acho que é assim. Chega uma hora que você vai ter uma sensibilidade. Que nem eu, eu acho que eu consegui trabalhar bem isso, chegar ao limite de dizer "Peraí. Agora é aula. Chegou no limite". Já teve momento também de uma aula que assim, não tão prestando atenção na aula porque tão com problemas em casa, daí a gente teve que sentar, conversar e falar "Pera aí, o que que tá acontecendo? E aí não é mais a professora. Você é uma pessoa. "Você não tem com quem conversar? Pode conversar comigo". Mas não no ponto de eu chegar e falar "Não, eu te ajudo, eu vou na sua casa”. Não ao ponto de fazer assim.

Mônica: Mas existe um envolvimento aí.

Anna: Exatamente, mas eu acho que aí tem um limite.

O fragmento (relativo à discussão sobre o filme Mentes Perigosas) mostra o questionamento sobre o grau de envolvimento que um professor pode chegar a ter com os estudantes. Para as alunas, é preciso que o professor encontre um ponto de equilíbrio ("um meio termo") nessa relação, para que o envolvimento não se confunda com uma relação entre amigos. 
Os alunos questionaram, também, o papel que a escola desempenha, atualmente, na educação das crianças:

Jamile: A escola perde o valor de escola. A criança faz balé, judô, faz o diabo na escola, mas cadê as matérias de antes? Eu vivo isso. Você prepara tudo e a criança vai pintar van Gogh, porque é status social, porque ele vai pra casa e no meio dos amigos do pai, ele cita van Gogh e às vezes ele nem tem idéia de quem foi ele. Não sei, eu vejo a escola como aquela colchinha de retalhos. O importante é o produto que a criança vai mostrar.

Serena: Mas você pode trabalhar com van Gogh e não é só arte que dá pra trabalhar com ele.

Jamile: É, mas você tem que ter a vontade de trabalhar. Tendo vontade, você tem como colocar em prática o que você acha que é essencial.

A preocupação destacada por Jamile e contestada por Serena residia no fato de algumas escolas privilegiarem atividades e conteúdos que fogem àqueles tradicionalmente compreendidos como mínimos e necessários, nas áreas disciplinares (de línguas, matemática, ciência etc). Para Jamile, em lugar de desenvolver conteúdos, que proporcionariam o desenvolvimento dos "conceitos científicos” (Vygotsky, 1934/1999), as escolas valorizam a arte, mas sem fazer dela um objeto para a construção do conhecimento da criança. Ao contrário, as artes são meramente figurativas; são introduzidas de forma desarticulada com o todo e cumprem simplesmente a função de "dar status".

Quanto aos conceitos abordados neste segundo momento do curso - aspecto que se configurou novamente como tema estruturante do fenômeno neste momento -, cabe destacar que eles não haviam sido previamente definidos por mim, professora, mas surgiram das necessidades expressas pelos alunos. Os dois subtemas que emergiram dos textos, 
neste caso, se referem às reflexões dos alunos a respeito de diferentes teorias de ensino e da visão de aprendizagem significativa. Os fragmentos abaixo ilustram um momento de discussão relacionado a teorias de ensino:

Mônica: Então transmitir é dar significado?

Anna: Eu acho que não, eu acho que é só uma outra forma de dizer passar o conteúdo, transmitir e passar, não sei.

Mônica: Que outra palavra você escolheria para expressar essa outra idéia que a Serena está elaborando?

Darlene: Mediar o conteúdo, mediar.

Inae: É que é assim: eu não fui buscar nada em relação a passar e transmitir, mas eu, no meu ponto de vista, eu acho que tem uma diferença, entre transmitir e passar, porque eu posso passar e o aluno não absorver, e outras situações em que se tem a responsabilidade de transmitir para o aluno a absorver, eu acho que é uma responsabilidade maior...

A discussão que se colocou em pauta gerou a necessidade de esclarecer melhor as teorias implícitas no uso dos termos passar e transmitir conhecimento, como o apoio de leituras, o que ampliou as oportunidades de reflexão sobre o assunto.

Outra particularidade do Momento 2 foi o surgimento do tema Buscas, revelando que, nessa etapa do curso, os meus alunos começaram, de fato, a aprofundar as relações entre ficção e realidade e entre os filmes aos quais assistiam e aspectos de ordem teórica. É o que fica evidente neste fragmento, que ilustra a forma como um aspecto teórico anteriormente tratado em aula - a concepção de ensino pautada na transmissão de conhecimentos - motivou uma aluna a empreender uma busca de respostas às suas dúvidas: 
Serena: Bom, (...) na aula anterior a gente discutiu passar e transmitir, e eu fui para a casa com a idéia de passar e transmitir. Alguns autores falam de passar e transmitir de uma forma diferente que a gente tem ouvido. Para eles passar é diferente de transmitir, por quê? Porque de acordo com a Regina Haidt, para a pessoa transmitir tem que haver um compromisso; há uma organização maior de um envolvimento. Por isso ela define de forma diferente. O passar é para ela como se chegar na lousa, colocar matéria e pronto acabou, isso é o passar o conteúdo. Já o transmitir envolve uma série de responsabilidades, tem aí também a critério de responsabilidade, selecionar material e a responsabilidade com a construção intelectual do aluno, e o professor tem que se sentir responsável por essa construção intelectual.

Considerando essas reflexões, percebo que, no Momento 2, houve uma maior tendência dos alunos ao estabelecimento de relações entre as práticas observadas nos filmes e teorias que pudessem embasá-las ou explicálas. Nessa perspectiva, considero que essa atitude mais investigativa que, em geral, marcou os alunos neste segundo momento, é indicativa de uma postura críticoreflexiva, desencadeada e em desenvolvimento de maneira mais intensa.

Noquedizrespeitoaalgumaspossíveiscomparações entre as estruturas desses dois primeiros momentos do curso, destaco que, na estrutura do Momento 1, o tópico Inter-relações possui o status de um sub-sub-subtema, vinculado ao sub-subtema Olhar Crítico que, por sua vez, se articula ao subtema Reflexão, associado ao tema Conceito (ver diagrama 1). No Momento 2, entretanto, as Inter-relações se manifestam de forma mais marcante, ganhando a dimensão de um subtema, devido ao destaque com que emergem das reflexões desencadeadas nessa fase do curso. 


\subsection{Momento 3}

Da interpretação dos textos reunidos no Momento 3, emergiram novamente os temas Questionamentos e Buscas, com novos desdobramentos, como vemos a seguir:

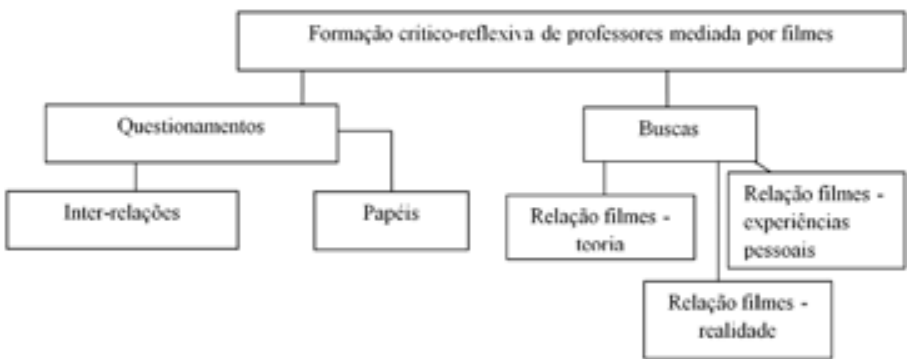

Fig. 3: A estrutura do fenômeno no Momento 3

Conforme ilustra o diagrama, o Momento 3 consolida os questionamentos e as buscas como os temas estruturadores do fenômeno da formação crítico-reflexiva de professores mediada por filmes. Particularmente, a reincidência do tema questionamentos, presente nos três momentos, marca, mais notoriamente, o percurso dos alunos e é resultado das inquietações provocadas pelos filmes e atividades a eles associadas.

Outro aspecto a ressaltar é que o tema Buscas manifestou-se de maneira mais intensa no Momento 3, consolidando aquelas que começaram a despontar no momento anterior. A presença mais enfática de buscas, na fase final do curso, demonstra um amadurecimento dos alunos, que revelaram uma maior capacidade de estabelecer relações entre os filmes e sua realidade, suas experiências pessoais e também com questões teóricas. $\mathrm{O}$ trecho abaixo exemplifica essas relações:

Geovana: E aí essa diretora manda um fiscal para avaliar a escola deles.

Serena: É o que acontece geralmente na periferia quando uma escola grande quer engolir uma 
pequena. Ela manda alguém lá porque não quer que

a escola vá para a frente e isso acontece no filme.

As ponderações feitas pelas alunas apontam para problemas enfrentados, atualmente, por professores e instituições brasileiras, o que demonstra sua capacidade de aproximar a ficção (dos filmes por elas analisados) da realidade.

\subsection{Transformações}

Ao chegar à etapa final de interpretação dos textos coletados durante o curso, percebi que os alunos viveram um processo reflexivo que gerou diversas transformações. A manifestação dessas mudanças, na minha perspectiva, foi tão expressiva, que as interpretei como um novo tema que vem somar-se àqueles que se manifestaram ao longo dos três momentos do curso.

Cabe dizer que as transformações vivenciadas durante o curso são de distintas naturezas, e se referem: a) às novas percepções dos alunos sobre os filmes; b) aos novos conhecimentos construídos; c) às novas percepções que passam a ter de si mesmos; e d) às novas ações que começam a marcar sua própria prática. Os excertos destacados a seguir exemplificam algumas dessas transformações:

Antes do curso, meu olhar crítico não fazia tanto essa junção da ficção sobre a pedagogia com a realidade da mesma. Hoje percebo esse tipo de reflexão como uma ferramenta grandiosa no processo de minha formação, que é algo contínuo, interminável.

Sinto-me cheia de novas idéias em relação ao ato de educar e instigada sobre a minha capacidade de educar. Sem dúvida a ficção ajudou minha realidade. Sou muito mais reflexiva agora. 
Antes, eu não selecionava textos para relacionar com os filmes. Meus critérios para seleção de filmes eram voltados somente aos meus interesses. Agora eu consigo visualizar melhor e encaminhar tudo o que peço e que ocorre em sala de aula. Observo melhor os critérios para tudo que vou fazer, respeito mais as idéias e opiniões dos alunos.

Acredito que os subtemas vinculados ao tema transformações sintetizam as contribuições que o processo reflexivo trouxe para os alunos. Conforme destaquei anteriormente, este tema se soma a todos os outros que emergiram ao longo dos três momentos do curso, constituindo, no final, a estrutura do fenômeno da formação crítico-reflexiva de professores mediada por filmes.

\subsection{0 fenômeno em seu conjunto}

A descrição e interpretação de cada um dos momentos em que se dividiu o curso revelou, pouco a pouco, a estrutura e a natureza do fenômeno que estava investigando. Ao olhar para os três momentos em seqüência, observo que o Momento 2 configurase como uma fase de transição entre os passos dados no início do curso em direção ao desenvolvimento da capacidade reflexiva de meus alunos (Momento 1 ) e os passos que levaram a uma maior consolidação dessa capacidade (no Momento 3), culminando, finalmente, no desencadeamento de transformações em meus alunos.

Essa visão processual também se faz presente na representação gráfica que resultou da interpretação do fenômeno como um todo, e que reúne os temas que emergiram nos diferentes momentos, como ilustra o diagrama abaixo: 


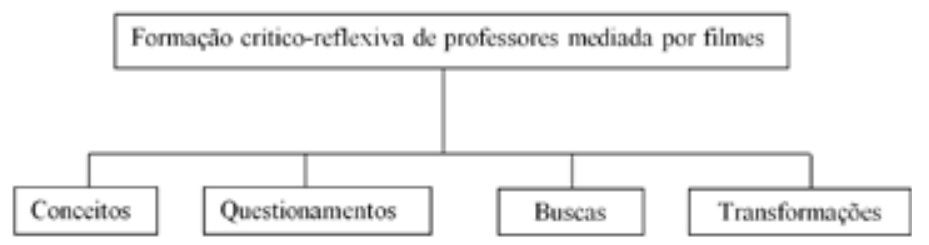

Fig. 5: Temas estruturantes do Fenômeno da formação críticoreflexiva de professores mediada por filmes

O tema Conceitos compreende os referenciais teóricos trabalhados durante o curso, que contribuíram para o desenvolvimento de uma prática refletida, comprometida e responsável, configurando-se, assim como práxis (FREIRE, 1983). O surgimento desse tema nos dois primeiros momentos do curso evidencia a importância da mediação do professor para que se estabeleça a relação entre a teoria e a prática (relação essa que, como se viu, já se manifestou de maneira espontânea no Momento 3, na forma de buscas empreendidas pelos alunos).

$\mathrm{O}$ tema Questionamentos refere-se às problematizações expressas pelos alunos ao longo de todo o curso, no âmbito do papel desempenhado pelo professor e pelo aluno no processo de aprendizagem, das inter-relações entre os diferentes participantes do processo de ensino-aprendizagem, e das experiências pessoais na construção do conhecimento sobre a docência. Como se viu, os alunos apresentaram uma postura indagadora ao longo de todo o processo, mas ela se revelou mais aprofundada e significativa a partir do segundo momento.

O tema Buscas expressa as atitudes desencadeadas durante o processo crítico-reflexivo vivido no curso, principalmente em decorrência do uso de filmes, que levaram os alunos a procurar estabelecer relações diversas entre esse signo mediador da reflexão e outros elementos de referência para eles: a realidade, a teoria e a sua experiência pessoal. 
Estruturando o fenômeno da formação críticorefexiva de professores mediada por filmes, também emerge o tema Transformações. Ele revela as mudanças ocasionadas pela experiência de formação compartilhada, na forma do reconhecimento, por parte dos alunos, da nova percepção que passam a ter sobre os filmes e sobre si mesmos, bem como dos conhecimentos construídos e das novas ações que pretendem incorporar à sua prática (atual e futura).

Ao observar a estrutura que se configurou acima, vejo indícios de que a capacidade reflexiva dos alunos foi sendo construída gradualmente, em direção a uma postura cada vez mais crítica.

\section{Reflexões finais}

O uso dos filmes como elementos desencadeadores e mediadores da reflexão crítica demonstrou que eles constituem, de fato, um recurso com potencial para enriquecer os programas de formação de professores, seja no âmbito da formação inicial ou continuada. Os filmes - produções que estão ao alcance de todos representam uma importante alternativa para os recursos freqüentemente utilizados, tais como diários, narrativas, gravações de aulas dos próprios professores em formação ou observações de aulas dos colegas, por exemplo. São artefatos que permitem ao docente em formação atribuir significados a diferentes ações pedagógicas e compreender as teorias que as embasam. Contribuem também para que o professor cresça na percepção de sua própria realidade e no conhecimento de outras, aparentemente alheias e distantes. Sob uma perspectiva mais ampla, o uso do filme pode colaborar, ainda, para que o professor tome decisões e se posicione criticamente frente às mudanças que caracterizam as novas formas de ensinar e aprender que marcam a sociedade contemporânea. 


\section{Referências}

ALMEIDA, M. J. Imagens e sons. A nova cultura oral. São Paulo: Cortez, 2001.

CONTRERAS, J. A autonomia de professores. São Paulo: Cortez, 2002.

COSTA, C. Educação, imagem e mídias. São Paulo: Cortez, 2005.

DEWEY, J. How we think. Lexington: D.C. Heath and Company, 1933.

DEWEY, J. Experience and Education. New York: Collier Books, 1938/1967.

DIAMOND, P. Mirrors and metaphors: Arts-based English teacher education, 1997.

Disponível em: <http://www.nyu.edu/education/teachlearn/ ifte/diamond.htm>. Acesso em 30 de maio de 2009.

DIAMOND, P. Arts-Based Inquiry and Teacher Reflection: a Teacher Institute. the ESPecialist, vol. 19, no2, p.215-231. São Paulo: EDUC, 1998.

FREIRE, M. M. Processo de tematização na abordagem Hermenêutico-Fenomenológica. Seminário: Desenhos de pesquisa para a ambientação presencial e/ou digital. PUC/SP, 2006.

FREIRE, M. M. A abordagem hermenêutico-fenomenológica como postura metodológica na investigação da formação docente. Apresentação em Simpósio durante o II CLAFPL - II Congresso Latino-Americano de Formação de Professores de Línguas, Rio de Janeiro, 2008.

FREIRE, P. Educação e Mudança. São Paulo: Paz e Terra,1979.

FREIRE, P. Texto oferecido na disciplina "Educação Popular" no curso de Pós-Graduação, ministrado por Paulo Freire. PUC/SP, 1982. 
FREIRE, P. Extensão ou Comunicação? 7ª ed. São Paulo: Paz e Terra, 1983.

KEMMIS, S. Critical reflection. In M. F. Wideen \& I. Andrews (orgs.) Staff development for school improvement. A focus on the teacher. Philadelphia: The Falmer Press, 1987.

MAYRINK, M. F. Luzes... câmera... reflexão: formação inicial de professores mediada por filmes. Tese de Doutorado. Programa de Estudos Pós-Graduados em Lingüística Aplicada e Estudos da Linguagem, Pontifícia Universidade Católica de São Paulo, 2007.

PIMENTA, S. G. Professor Reflexivo: construindo uma crítica. In S. G. Pimenta \& E. Ghedin (orgs.) O professor reflexivo no Brasil: gênese e crítica de um conceito. São Paulo: Cortez Editora, 2002.

POLANYI, M. The tacit dimension. New York: Doubleday Anchor Book, 1967.

RICOEUR, P. Del texto a la acción. Ensayos de Hermenéutica II. México D.F.: Fondo de Cultura Económica, 2001.

SCHÖN, D. A. The reflective practitioner - How professionals think in action. Cambridge: Basic Books, 1983.

SCHÖN, D. A. Educating the reflective practitioner. San Francisco: Jossey-Bass Publishers, 1987.

SCHÖN, D. A. The theories of inquiry: Dewey's legacy to education. Curriculum Inquiry, vol.22, no2, p.119-139, 1992.

SMYTH, J. Teacher's Work and the Politics of Reflection. In American Educational Research Journal, vol.29, o2, p.267-30, 1992.

van MANEN, M. Researching lived experience. London, Ontario: Althouse Press, 1990.

VYGOTSKY, L. S. A formação social da mente. São Paulo: Martins Fontes, 1930/1998 
VYGOTSKY, L. S. Pensamento e Linguagem. São Paulo:

Martins Fontes, 1934/1999.

ZEICHNER, K. M. A Formação Reflexiva de Professores:

Idéias e Práticas. Lisboa: Educa, 1993.

Recebido em 28/02/2014

Aceito para publicação em 30/07/2014 